\title{
Risky Lifestyles and Unintentional Firearms Fatalities
}

\author{
Rick Ruddell $^{1}$ and G. Larry Mays ${ }^{2}$ \\ ${ }^{1}$ California State University, Chico \\ ${ }^{2}$ New Mexico State University
}

\begin{abstract}
This state-level study departs from other investigations of unintentional firearms fatalities by examining the relationships between lifestyle choices, legislation, and accidental gun deaths. We find that the source of these deaths is very similar to those for unintentional fatalities from other mechanisms, such as motor vehicle accidents, residential fires, or occupational injuries. Unintentional mortality is consistently associated with state-level indicators of risky behavior, and to a lesser extent, inactivity. Moreover, we also examined the influences of child access prevention (safe storage), overall firearms laws, and background checks on firearms fatalities. Unlike previous research, we found that these legislative initiatives were not significantly associated with reductions in accidental shooting deaths. Our findings suggest that theories about unintentional fatalities will remain incomplete and harm reduction policies, including the public health model endorsed by many scholars, will not be fully effective if the role of risktaking and sensation-seeking behaviors as an important source of these tragedies is neglected.
\end{abstract}

(C) 2004 Californian Journal of Health Promotion. All rights reserved.

Keywords: Unintentional Injuries, Firearms Legislation, Accidental Death, Firearms Mortality

\section{Introduction}

Few scholars have acknowledged the dramatic reductions in the rates of unintentional firearms fatalities over the past three decades. Kates (2001), for example, reports that in 1968 2,896 persons -- or 1.44 persons per 100,000 residents in the population -- were victims of unintentional firearms fatalities. In the year 2001, by contrast, 802 Americans died in accidental shootings, representing a rate of .28 persons per 100,000 residents in the population (Centers for Disease Control \& Prevention, 2003).

There are a number of explanations for the decrease in unintentional firearms fatalities. Some of these reasons may not relate to actual incidents themselves. Kleck (1991) asserts that more accurate reporting of suicides or classification of homicides has lead to decreasing rates of accidental deaths. Barber et al. (2002), by contrast, argue that the number of unintentional firearm fatalities is undercounted (see also Schaechter et al., 2003).
Coroners or the police today may be less likely to classify a firearms suicide as an accident (Hanzlick, Hunsaker \& Davis, 2002). Moreover, increases in the sophistication of crime scene analysis might also correctly classify some "staged" firearms accidents (or suicides) as homicides (Geberth, 1996; Turvey, 2000).

Other reasons for reductions in fatal accidents also might be attributed to changes in social trends, improvements in trauma care, and changes in our willingness to take risks. Increasing urbanization and decreasing numbers of people who hunt might have contributed to fewer recreational shooting or hunting accidents. A national-level survey recently found, for instance, that self-reported hunting had decreased seven percent from 1991 to 2001 (U.S. Fish and Wildlife Service, 2002). This seven percent decline reflects part of a long-term trend of decreasing numbers of hunters (Warnick, 2000). 
In addition to reductions in the number of hunters, 48 states now have some type of regulation that restricts the issue of hunting licenses to those who have completed hunter education programs, or who were born after a specific date (International Hunter Education Association, 2004). Since 1949, for instance, some 25 million persons have received hunter education (IHEA, 2004). Thus, not only are there fewer hunters today, but those who are active are more likely to have had some form of hunter education, which might further reduce these injuries.

Another possible reason for reductions in accidental shooting deaths is that hunting firearms (primarily rifles and shotguns) generally have a higher capacity for lethality, compared to handguns typically used for selfdefense or sport (Ruddell \& Mays, 2002). In a recent study, Nance et al. (2003) found higher rates of unintentional firearms fatalities in rural counties, and attributed this finding to greater involvement of long-guns. Though firearms are more prevalent today than in previous years -the estimated national stock of firearms is 276 million -- most firearms sold today are handguns (Bureau of Alcohol, Tobacco and Firearms, 2000). Establishing the true number of firearms in the United States is a somewhat contentious exercise. There are estimated to be some 238 to 276 million firearms in circulation (Graduate Institute of International Studies, 2003) and this total increases by some 4.5 million firearms per year (Bureau of Alcohol, Tobacco \& Firearms, 2000).

While wounds from small caliber handguns are still very life-threatening, they have less capacity for lethality than rifles and shotguns (DiMaio, 1985). A recent study of unintended shootings in Atlanta, for instance, revealed that handguns were involved in 87 percent of all such injuries (Ismach et al., 2003).

A second reason for reductions in unintentional firearms deaths is that today we are more likely to be conscious about our health and to avoid risks of various kinds. Some of our awareness of firearms risks may be due to the large number of interest groups, including organizations that advocate for restricting the possession, use, and access to firearms. Neal (2000, p. 13) observes that: The exposure, discussion, and elimination of real or potential risks has become a primary political concern. Any risk of disease or death, no matter how small, is newsworthy and the need to eliminate even minor risks goes unquestioned, contributing to a widespread fatalism in the face of ever-tightening health and safety regulations.

This increasing interest in risk aversion has undoubtedly made us more conscious of unhealthy or dangerous practices. It is possible that such concerns as these have motivated us to be more careful in handling firearms.

A final reason for the reduction in accidental death rates from firearms injuries is that victims of gunshot wounds entering emergency departments (ED) are much more likely to survive today than their predecessors a few decades ago (Harris et al., 2002). Jaret (2000) for example, reports that over 100,000 Americans survive gunshot wounds each year. Survivability of gunshot wounds has been influenced by a number of factors over which health professionals have no control - the location of injury and intent, for instance (see Beaman et al., 2000). But, emergency care has improved, including faster delivery of patients to trauma care and the increasing specialization of ED physicians (Firearms Injury Center at Penn, 2002). The decreasing mortality rates from gunshot wounds are especially noteworthy during an era when gunshot victims frequently are shot with handguns with a greater capacity for lethality (see Caruso, Jara \& Swan 1999).

\section{Risky Behavior and Unintentional Fatalities}

While many people are more careful and risk averse today, there are indicators that this phenomenon is not universal. The federal government has established an inventory of Leading Health Indicators, which suggests that while many individuals are risk-averse, and pursue very healthy styles of living, there is a sub-group within the population that has high rates of obesity, inactivity, substance abuse, tobacco use, and irresponsible sexual behavior (U.S. Department of Health and Human 
Services, 2000). It is possible that this subgroup within the population may be more at risk of unintentional injuries of all types, including firearms accidents. Better understanding the behavioral sources of these unintentional fatalities, for instance, might enable us to focus public health efforts more carefully.

Klein (1980), for example, observed that many urban victims of unintentional accidents tended to keep firearms loaded and unlocked for selfprotection. Many of the persons involved in his study were characterized as having lifestyles that were irregular, unplanned, and disorderly (Klein, 1980). These results are consistent with an earlier study of firearms fatalities in urban populations that found that half of the persons involved in these shootings had been drinking alcohol prior to the event (Rushforth et al., 1974). These findings are important when one considers that as many as 20 million firearms are left loaded and unlocked in American homes (Wintemute, 2000, p. 58).

Kleck (1991, p. 286) extended Klein's observations, and asserted that individuals who were involved in unintentional firearms accidents were likely to have personal characteristics that were very close to those who were involved in intentional violence, including "personality traits, such as poor aggression control, impulsiveness, alcoholism, willingness to take risks, and sensation seeking." Kleck (1991, p. 285) hypothesizes that the factors that contribute to high rates of vehicle accidents also contribute to fatal firearms accidents: "Accidentinvolved drivers are commonly characterized by family disruption and conflict, both in their adult lives and in their childhood, poor employment records, fewer friends, sexual promiscuity, and irresponsibility toward their families.” A recent study of motor vehicle accidents, for instance, found that high hostility, poor self-esteem, and high job stress all were positively associated with motor vehicle accidents (Norris, Matthres \& Riad, 2000). It is very plausible that similar factors might influence rates of firearms injuries as well.

In a recent study, Ruddell and Mays (2004) found that indicators of high-risk behavior -such as alcohol and drug use, or high rates of teen birth rates and sexually transmitted diseases -- consistently were associated with unintentional juvenile firearms fatalities. Moreover, states that had enacted child access prevention laws were associated with reductions in unintentional firearms fatalities in the general population, but not in juvenile populations. These findings suggest that the relationship between behavioral characteristics and these fatalities should be examined more closely.

In order to evaluate whether firearms mortality is associated with other types of unintentional fatalities, we use mortality data from the CDC for the general population from 1999 to 2001 and average these years to account for temporal variation. The state rate of emergency department visits also was included, as this was hypothesized as being associated with risky behavior as well. With few exceptions, there is a high association among these different indicators of unintentional mortality.

In fact, firearms fatalities were strongly associated with all other types of unintentional mortality, and emergency department visits. This finding suggests that the same factors that contribute to motor vehicle fatalities or residential fire deaths also might contribute to firearms fatalities.

In recent years there has been more scholarly interest in examining the behavioral characteristics of victims of unintentional injuries. Most of the accident literature, however, has focused upon personality factors, sensation seeking, or risk-taking behaviors in drivers, and whether those traits are associated with higher involvement in motor vehicle crashes (see Peltzer \& Renner, 2003; Sumer, 2003). 
Table 1

Correlation of 1999-2001 State Unintentional Fatalities, Means and Standard Deviations ${ }^{1}$

\begin{tabular}{|l|l|c|c|c|c|c|c|r|r|}
\hline & & $\mathbf{( 1 )}$ & $\mathbf{( 2 )}$ & $\mathbf{( 3 )}$ & $\mathbf{( 4 )}$ & $\mathbf{( 5 )}$ & $\mathbf{( 6 )}$ & Mean & s.d. \\
\hline 1 & All Mechanisms & ----- & & & & & & 38.63 & 8.70 \\
\hline 2 & Motor Vehicle & $.920^{* *}$ & ----- & & & & & 17.02 & 5.47 \\
\hline 3 & Residential Fire & $.545^{* *}$ & $.576^{* *}$ & ----- & & & & 1.12 & .53 \\
\hline 4 & Drowning & $.583^{* *}$ & $.480^{* *}$ & $.333^{*}$ & ----- & & & 1.35 & .58 \\
\hline 5 & Occupational & $.700^{* *}$ & $.622^{* *}$ & $.288^{*}$ & $.776^{* *}$ & ----- & & 5.53 & 3.26 \\
\hline 6 & E.D. Visits & .206 & $.296^{*}$ & $.642^{* *}$ & -.052 & -.003 & ----- & 377.96 & 76.64 \\
\hline 7 & Firearms & $.807^{* *}$ & $.836^{* *}$ & $.704^{* *}$ & $.384^{* *}$ & $.444^{* *}$ & $.401^{* *}$ & .34 & .25 \\
\hline
\end{tabular}

1. Occupational Fatalities and Emergency Department visits are for the years 2000 and 2001 only, and were obtained from the Kaiser Family Foundation. All other data were obtained from the Centers for Disease Control and Prevention, and average 1999 to 2001 data (includes all ages). Mortality data is expressed in a rate per 100,000 residents, while the ED visit variable is the rate per 1,000 residents.

In a comprehensive review of such studies, Turner, McClure, and Pirozzo (2004) found that investigators most often examined traffic accidents, and typically found that alcohol and seat belt use, involvement in prior accidents, and traffic tickets were associated with higher rates of fatalities. Moreover, a recent group of studies also has examined the relationship between motor vehicle accidents and cultural values such as fatalism (Sumer, 2003) or superstition (Peltzer \& Renner, 2003). Similar research also has found that individual characteristics such as hyperactivity are associated with an increased probability of involvement in major accidents (Lalloo, Sheiham \& Nazroo, 2003).

Given the high association between unintentional firearms fatalities and other mechanisms of injury, as well as this emerging literature that has outlined the relationship between risky behavior and accidents, this study examines the issue more closely using statelevel analyses. First, we examine the association between state level indicators of risky or sensation-seeking behaviors and unintentional fatalities and emergency department visits. Second, we focus more closely on unintentional firearms fatalities, including variables more specific to these analyses, including indicators of firearms density, and a number of legislative variables.

\section{Data and Analytic Strategies}

This study uses ordinary least squares (OLS) regression models to evaluate whether risky or sensation-seeking behaviors are associated with unintentional fatalities. Most previous studies of accidental deaths have focused upon various demographic characteristics, typically age or race. Moreover, such studies often control for structural characteristics, such as poverty or socioeconomic status. The present research departs somewhat by controlling for a number of variables highly associated with individual risktaking behavior. Many of the variables used in this study are similar to the Leading Health Indicators outlined by the HHS (2000). Our intention is to discover whether there is a common set of underlying behavioral characteristics that contribute to higher rates of fatalities irrespective of the mechanism of injury.

In the second series of analyses, unintentional firearms fatalities are more closely examined, and we also control for the number of firearms in circulation (a concept commonly known as the firearms density), and a number of legislative variables including the presence of child access prevention legislation, whether a state has comprehensive background checks (to screen for whether the purchase of a firearm may be denied), and the permissiveness of a state's overall gun laws. A number of recent studies have found that higher rates of firearms density are associated with increased risk of unintentional injuries (Miller et al., 2001; 2002; Weibe, 2003). There is an intuitive appeal to this finding, as there is less likelihood of a firearms injury if there are few guns within a 
jurisdiction. But it is also plausible that higher rates of individuals who engage in risky behavior may be more likely to influence the rate of accidents, irrespective of the number of firearms in circulation or the types of gun laws enacted.

Because of the limited number of cases in a state-level analysis, this study makes extensive use of factor analyses to combine a number of variables that are theoretically associated with each other, and are also highly correlated. In addition to reducing the regressor space between the variables, factor analyses actually may be more likely to capture the true element of risktaking because the process reduces the error within a single index. The following sections outline the variables used, the sources of data, as well as the characteristics of the individual variables. In the case of the variables used in the construction of the two factors used in this research, they are reported in Appendix C.

\section{Dependent Variables}

Unintentional fatality data for firearms, motor vehicle accidents, residential fires, and drowning were obtained from the CDC, and are expressed in rates per 100,000 residents in the population from 1999 to 2001. Statistics from all three years are included in the study to reduce temporal variation. Information about workplace fatalities and emergency department visits, by contrast, were retrieved from the Kaiser Family Foundation website. The workplace injury data were originally circulated by the Bureau of Labor Statistics and are expressed in a rate per 100,000 residents in the population, while the American Hospital Association disseminated the ED visit statistics, and these involve the rate per 1,000 residents in the population. Both of the indicators retrieved from the Kaiser Family Foundation average 2000 and 2001 data. Examination of these statelevel fatality data, including skewness and kurtosis, revealed that most variables had distributions that were approximately normal. Two of the indicators, the rate of persons drowned and occupational fatalities, had distributions that were skewed, suffered from severe kurtosis, and consequently these variables were log-transformed.

\section{Independent Variables}

Percentage Population that is Urban. First, we control for the percentage of the state that is urban, using 2000 U.S. Census data. Hunting and shooting accidents are commonly characterized as rural events. Kleck (1991), however, suggests that unintentional firearms fatalities are more common in urban areas, and they are associated with the use of handguns as defensive weapons. By contrast, however, recent studies have found higher rates of unintentional firearms fatalities in county (Nance et al., 2003) and state (Ruddell \& Mays, 2004) populations. It is possible that in some rural areas -especially those without advanced life support systems that provide pre-hospital care -- there will be higher unintentional death rates irrespective of the mechanism of injury (Svenson et al., 1996).

Risky Behavior Factor. Consistent with Kleck's (1991) observations about the behavioral characteristics of people involved in accidental shootings, a number of Leading Health Indicators were identified, including rates of sexually transmitted diseases (gonorrhea and chlamydia), alcohol use, smoking, and the teen birth rate. These data were obtained from a number of sources, including the CDC (sexually transmitted diseases), National Center for Health Statistics (the teen birth rate per 1,000 residents in the population, and the percentage of the state population that self-reported smoking), and the National Institute for Alcohol Abuse and Alcoholism (per capita ethanol consumption).

Factor analysis was used to reduce these highly correlated data and we found that all five of these indicators loaded into one variable that we label "risky behavior." We hypothesized that states that are characterized as having high rates of risky behavior would have higher rates of unintentional fatalities -- whether from firearms or other mechanisms -- in comparison with more risk-averse and presumably healthier states.

Inactivity Factor. Two different leading health indictors, however, were not highly associated with the risky behaviors, the percentage of the state population that is obese, and the number of 
days that a person was inactive due to mental or physical illness. These data were both obtained from the National Center for Health Statistics. Both of these variables, however, were highly correlated with each other, so factor analysis was used once more to construct an indictor that we have labeled "inactivity." Again, we hypothesized that inactivity also would be associated with higher rates of unintentional injury or mortality.

Seat Belt Use. One tangible step that an individual can take to minimize injury is wearing a seat belt (Noland, 2003). We hypothesized that individuals who don't wear seat belts are unlikely to take other precautions to limit their exposure to injury. Seat belt usage data for 2000 and 2001 were obtained from the National Highway Traffic Safety Administration. Two cases, Maine and New Hampshire, were missing for both years, so these cases were mean-replaced (Greene, 2000). In 2001, data were missing for the state of Wyoming, so 2000 data were used for both years.

Firearms Variables. There is little agreement about the number of firearms in circulation regardless of the level of analysis. While some scholars have utilized composite variables that use a number of different indicators of the prevalence of firearms (i.e., Miller et al., 2001, 2002), this study uses a proxy measure of firearms density - the percentage of all suicides that used firearms. This variable generally has been accepted methodologically in the firearms literature (Azreal, Cook \& Miller, 2004; Kleck, 2001).

Firearms Legislation. In contrast to estimating firearms density within a jurisdiction, it is somewhat easier to evaluate whether a state's policies on firearms ownership, requirements for purchasing, licensing or restrictions on storage and use are permissive or restrictive. This study uses state indicators developed by the Open Society Institute (2000) that range from states with strict regulation of firearms (Massachusetts, with a score of plus 76) to states that place fewer restrictions on firearms (Maine, with a score of minus 10). Analysis of these ratings revealed that the distribution was skewed and subsequently they were log-transformed.

A second measure of firearms regulation, whether a state's "Background Check System" for firearms purchases is comprehensive and automated, was obtained from the Americans for Gun Safety Foundation (2002). Every purchaser of a firearm from a federally licensed firearms dealer first must be checked through national and state registries of ineligible purchasers, including those with domestic violence restraining orders, mental health records, and/or disqualified misdemeanants. The AGS rated each state on a scale of 100 , based on a state's ability to screen automatically ineligible persons. The scale ranged from those states with highly effective screening mechanisms (North Carolina with a score of 89) to states that have fewer automated or comprehensive systems (Indiana with a score of 5). Maryland data were missing, so this case was mean-replaced. Previous research has demonstrated that states with less comprehensive background checks are significantly associated with higher rates of firearms homicides (Mays \& Ruddell, 2003). In their study, Mays and Ruddell (2003) empirically evaluated this scale, and found it to be a valid indicator. Given the relationship between background checks and reductions in violence, it is possible that limiting the number of inappropriate users also may reduce unintentional firearms fatalities.

The third indicator of firearms legislation is whether the state had adopted child access prevention (CAP) or "safe storage" legislation. Although previous investigators have reported ambiguous results (Cummings et al., 1997; Lott \& Whitley, 2001; Teret \& Webster, 1999), it is hypothesized that these laws may reduce both adult and juvenile unintentional deaths by reducing access to unauthorized persons, especially children. Data were obtained from the Brady Campaign (2003, p. 1), a group that defines this type of legislation as holding "adult gun owners responsible if they leave guns easily accessible to children and a child improperly gains access to the weapon." A dummy variable was created that represents the 18 states that have introduced CAP between 1989 and 1999. 
States that have enacted CAP legislation are California, Connecticut, Delaware, Florida, Hawaii, Illinois, Iowa, Maryland, Massachusetts, Minnesota, Nevada, New Hampshire, New Jersey, North Carolina, Rhode Island, Texas, Virginia, and Wisconsin. We included New Hampshire in our analyses despite the fact that it introduced its CAP in 2000 - excluding this state had no effect on our findings in supplementary analyses.

\section{Results}

Zero-order correlations for the seven dependent variables and the four independent variables are reported in Appendix A and the variables specific to the firearms analyses reported in Appendix B. The results presented in Appendix $\underline{\text { A }}$ reveal that the independent variables are strongly associated with the seven dependent variables. This is an important finding because this study uses few of the traditional demographic or structural control variables. In fact, the only demographic variable -- the percentage of the population that is urban -- had a significant negative association with six of the seven dependent variables; the sole exception to this was emergency department visits. Given the fact that some hospital patients may use ED visits for reasons other than unintentional injury (i.e., chronic health conditions, or if they do not have access to a physician), this variable may not be a valid indicator of accidental injury.

The two variables of interest, risky behavior and inactivity, are strongly associated with the dependent variables, with the exclusion of occupational fatalities and ED visits. Inactivity, by contrast, was strongly associated with all of the dependent variables except occupational fatalities. Finally, the seat belt usage variable, an indicator of taking reasonable safety precautions, had a strong negative association with all of the dependent variables, but did not have a statistically significant association with drowning fatalities. Interestingly, the seat belt variable had a strong positive association with the percentage of the population that is urban suggesting that urban residents may be more likely to wear seat belts than their rural counterparts.
The firearms specific analyses contribute a number of additional variables, including the firearms density (the percentage of all suicides that used firearms), a dummy variable for the states that had enacted child access prevention legislation, overall firearms laws, and whether a state had comprehensive background checks. All four of these variables had significant relationships with firearms fatalities. The firearms density variable had a significant positive association while the legislative variables all had strong negative associations. Accordingly, states that did not enact child access prevention legislation, had less restrictive firearms laws, and provided less comprehensive background checks were all associated with higher rates of unintentional firearms fatalities. Again, these strong bivariate findings suggest that the OLS models will be correctly specified.

Table 2 presents the results of seven OLS regression models estimated on the different indicators of unintentional fatalities and emergency department visits. The same model is used to assess the contribution of risky behavior and inactivity on the different dependent variables. This series of analyses demonstrates that the percentage of the state that is rural is strongly associated with all of the indicators, with the exception of ED visits. Second, the indictor of risky behavior had a strong positive association with all of the indicators of unintentional fatalities, but not ED visits. Again, two possible reasons for this finding are that ED visits may capture hospital admissions for reasons other than unintentional injuries, and there may be a lack of such facilities in rural areas.

The results reported in Table 2 demonstrate that the inactivity variable, as well as the indicator of seat belt use, had inconsistent relationships with the seven dependent variables. Inactivity, for example, had a positive association with ED visits, and both residential fires, and firearms fatalities. Seat belt use, by contrast, had a significant negative relationship with both ED visits and residential fire fatalities. Surprisingly, seat belt usage was not significantly associated with reductions in motor vehicle fatalities. 
Considering that only four variables were used in this series of analyses, and these indicators represent only behavioral characteristics, the model fit was surprisingly strong. Because condition indices were somewhat elevated in this series of analyses, however, we were reluctant to add additional control variables that would increase collinearity. Consequently, there is a strong possibility of omitted variable bias, yet these findings suggest that in four cases we explain approximately 70 percent of the variation in state-level unintentional fatalities using only these indicators of behavior. Consequently, our study provides some empirical evidence to suggest that the conditions that contribute to high rates of motor vehicle accidents, residential fires and, to a lesser extent, occupational injuries, also contribute to high rates of fatal gun accidents.

Table 2

Regression of State Unintentional Fatality Rates

\begin{tabular}{|c|c|c|c|c|c|c|c|}
\hline & Model 1 & Model 2 & Model 3 & Model 4 & Model 5 & Model 6 & Model 7 \\
\hline & $\begin{array}{c}\text { All } \\
\text { Mechanisms }\end{array}$ & $\begin{array}{l}\text { Motor } \\
\text { Vehicle }\end{array}$ & $\begin{array}{l}\text { Residential } \\
\text { Fire }\end{array}$ & $\begin{array}{c}\text { Drowning } \\
\text { ln }\end{array}$ & $\begin{array}{c}\text { Occupational } \\
\text { ln }\end{array}$ & $\begin{array}{l}\text { E.D. } \\
\text { Visits }\end{array}$ & Firearms \\
\hline & $\mathbf{b} / \boldsymbol{\beta}$ & $\mathbf{b} / \boldsymbol{\beta}$ & $\mathbf{b} / \boldsymbol{\beta}$ & $\mathbf{b} / \boldsymbol{\beta}$ & $\mathbf{b} / \boldsymbol{\beta}$ & $\mathbf{b} / \boldsymbol{\beta}$ & $\mathbf{b} / \boldsymbol{\beta}$ \\
\hline & (s.e.) & (s.e.) & (s.e.) & (s.e.) & (s.e.) & (s.e.) & (s.e.) \\
\hline Percent & $-.310 * * *$ & $-.185^{* * *}$ & $-.005^{*}$ & $-.010 * * *$ & $-.017 * * *$ & .515 & $-.005^{* * *}$ \\
\hline \multirow[t]{2}{*}{ Urban } & -.733 & -.697 & -.227 & -.579 & -.711 & .138 & -.479 \\
\hline & $(.041)$ & $(.024)$ & $(.003)$ & $(.002)$ & $(.003)$ & $(.491)$ & $(.001)$ \\
\hline Risky & $4.248^{* * *}$ & $3.030 * * *$ & $214^{* * *}$ & $.167 * *$ & $.187 * *$ & -5.236 & $.094 * * *$ \\
\hline \multirow[t]{2}{*}{ Behavior } & . 488 & .554 & .404 & .448 & .379 & -.068 & .379 \\
\hline & $(.845)$ & $(.503)$ & $(.053)$ & $(.051)$ & $(.060)$ & (10.203) & .026 \\
\hline \multirow[t]{3}{*}{ Inactivity } & .962 & .573 & $.229 * * *$ & .020 & .000 & $39.551^{* * *}$ & $.102 * * *$ \\
\hline & .110 & .105 & .433 & .056 & .002 & .516 & .405 \\
\hline & $(.870)$ & $(.518)$ & $(.054)$ & $(.052)$ & $(.062)$ & (10.505) & $(.025)$ \\
\hline Seat Belt & .044 & .006 & $-.010^{*}$ & .004 & -.000 & $-3.537 * * *$ & .000 \\
\hline \multirow[t]{2}{*}{ Usage } & .048 & .011 & -.190 & .113 & -.009 & -.434 & -.007 \\
\hline & $(.083)$ & $(.049)$ & $(.005)$ & $(.005)$ & $(.006)$ & $(1.004)$ & $(.002)$ \\
\hline Constant & 56.570 & 29.146 & 2.272 & .625 & 2.776 & 591.721 & .750 \\
\hline Adj. $r^{2}$ & .691 & .722 & .676 & .384 & .515 & .418 & .699 \\
\hline
\end{tabular}

* $\mathrm{p}<.05 ; * * ; \mathrm{p}<.01 ; * * * ; \mathrm{p}<.001 ; \ln =\log$ transformed

The series of analyses for the unintentional firearms fatalities are demonstrated in Table 3. Four different models are estimated, and they use the same variables as previously described, with one exception: the percentage of the state population that uses seat belts. This variable was omitted as it was not significantly associated with firearms fatalities, and it was replaced with a number of firearms-specific variables, including the prevalence (or density) of firearms, and three legislative variables. A baseline model that included the firearms density variable (the percentage of suicides that used firearms) is estimated, and the three legislative variables are added independently.
Model 1 reveals that consistent with our expectations states with higher rates of risky behavior, inactivity, and those states with greater rural populations are associated with higher rates of unintentional fatalities. The adjusted $\mathrm{r}^{2}$ statistic suggests that there is a good model fit. Inconsistent with our expectations, and previous research (Miller et al., 2001; 2002; Ruddell \& Mays, 2004), there was not a significant association with the indicator of firearms density and unintentional fatalities. Models 2 through 4 add three different indicators of firearms legislation. Net of the control variables, none of these legislative variables were statistically significant - although states that had enacted child access prevention legislation approached 
statistical significance $(p=.054)$. In all of these models the variance inflation factors were in the acceptable range (below 3.0) but the condition indices were somewhat elevated, and this precluded us from adding additional variables into the equations.

Table 3

Regression of 1999-2001 State Unintentional Firearms Fatalities

\begin{tabular}{|c|c|c|c|c|}
\hline & Model 1 & Model 2 & Model 3 & Model 4 \\
\hline & Firearms & $\begin{array}{c}\text { Child } \\
\text { Access Law }\end{array}$ & $\begin{array}{c}\text { Overall } \\
\text { Gun Laws }\end{array}$ & $\begin{array}{c}\text { Background } \\
\text { Checks }\end{array}$ \\
\hline & $\mathbf{b} / \boldsymbol{\beta}$ & $\mathbf{b} / \boldsymbol{\beta}$ & $\mathbf{b} / \boldsymbol{\beta}$ & $\mathbf{b} / \boldsymbol{\beta}$ \\
\hline & (s.e.) & (s.e.) & (s.e.) & (s.e.) \\
\hline \multirow[t]{2}{*}{ Percent Urban } & $\begin{array}{l}-.004^{* *} \\
-.384\end{array}$ & $\begin{array}{l}-.004^{* * * *} \\
-.347\end{array}$ & $\begin{array}{l}-.005^{* * * *} \\
-.439\end{array}$ & $\begin{array}{l}-.004^{* * * *} \\
-.370\end{array}$ \\
\hline & $(.001)$ & $(.001)$ & $(.001)$ & $(.001)$ \\
\hline \multirow[t]{2}{*}{ Risky Behavior } & $\begin{array}{l}.076^{* *} \\
.306\end{array}$ & $\begin{array}{l}.084^{* *} \\
.337\end{array}$ & $\begin{array}{l}.074^{* *} \\
.296\end{array}$ & $\begin{array}{l}.069 * * \\
.279\end{array}$ \\
\hline & $(.026)$ & $(.025)$ & $(.026)$ & $(.025)$ \\
\hline \multirow[t]{2}{*}{ Inactivity } & $\begin{array}{l}.087 * * * \\
.348\end{array}$ & $\begin{array}{l}.085^{* * *} \\
.343\end{array}$ & $\begin{array}{l}.087 * * * \\
.348\end{array}$ & $\begin{array}{l}.086 * * * \\
.346\end{array}$ \\
\hline & $(.025)$ & $(.025)$ & $(.025)$ & $(.025)$ \\
\hline \multirow[t]{2}{*}{$\begin{array}{l}\text { Firearms } \\
\text { Density }\end{array}$} & $\begin{array}{l}.004 \\
.196\end{array}$ & $\begin{array}{l}.002 \\
.099\end{array}$ & $\begin{array}{l}.006 * \\
.282\end{array}$ & $\begin{array}{l}.003 \\
.142\end{array}$ \\
\hline & $(.002)$ & $(.015)$ & $(.003)$ & $(.002)$ \\
\hline \multirow[t]{2}{*}{$\begin{array}{l}\text { Child Access } \\
\text { Law }\end{array}$} & ----- & $\begin{array}{l}-.096 \\
-.188 \\
\end{array}$ & ----- & ----- \\
\hline & & $(.003)$ & & \\
\hline \multirow[t]{2}{*}{$\begin{array}{l}\text { Overall Gun } \\
\text { Laws ln }\end{array}$} & ----- & ----- & $\begin{array}{l}.047 \\
.157 \\
\end{array}$ & ----- \\
\hline & & & $(.036)$ & \\
\hline \multirow[t]{2}{*}{$\begin{array}{l}\text { Background } \\
\text { Check }\end{array}$} & $\begin{array}{l}---- \\
-\end{array}$ & $\begin{array}{l}---- \\
-\end{array}$ & ----- & $\begin{array}{l}.002 \\
-.158 \\
\end{array}$ \\
\hline & & & & $(.001)$ \\
\hline Constant & .429 & .547 & .243 & .591 \\
\hline Adj. $r^{2}$ & .716 & .734 & .721 & .731 \\
\hline
\end{tabular}

$* \mathrm{p}<.05 ; * * ; \mathrm{p}<.01 ; * * * ; \mathrm{p}<.001 ; \ln =\log$ transformed 
Similar to the results reported in Table 2, therefore, this series of analyses reveals that risky behavior and inactivity are highly associated with unintentional firearms fatalities. Moreover, different types of firearms legislation, including the overall degree of gun law permissiveness, did not have statistically significant associations with reductions in fatal firearms accidents. Because demographic and structural variables were excluded in this study, our results are somewhat different than other recent studies (Cummings et al., 1997; Miller et al., 2001, 2002; Ruddell \& Mays, 2004). The implications of our findings for future research and policy development are discussed more fully below.

\section{Summary and Conclusions}

Controlling for a number of variables that are theoretically associated with previous research of unintentional fatalities, the findings reported here suggest that state levels of unintentional fatalities are highly associated with an indicator of risky behavior. In addition, unintentional fatalities had a consistent negative association with the population of the state that was urban. Moreover, our indicator of inactivity was a source of unintentional fatalities for three of the dependent variables examined in this study. Inconsistent with expectations, however, the percentage of drivers who wear seat belts was not associated with unintentional fatalities, but it was associated with higher rates of emergency department visits.

These findings provide empirical support to the scholarly argument that suggests that the conditions that lead to firearms fatalities are not characteristically different than other types of unintentional injuries. Firearms are dangerous objects, much like motor vehicles, and perhaps even more prevalent within our society -- in 2001, for instance, there were some 235 million registered vehicles (Bureau of Transportation Statistics, 2003). Policy-makers and interest groups alike have suggested a number of legislative acts that are intended to make firearms safer. Some of these suggestions include modifications to firearms design to reduce unintentional discharges or use by unauthorized persons (Frattaroli, Webster \&
Teret, 2002), while others suggest that new laws be enacted, such as child access prevention legislation. Still other interest groups want to ban certain types of firearms, including handguns.

Unintentional firearms fatalities have dropped consistently for some 30 years - during a time when the prevalence of firearms has increased steadily (Kates, 2001). Given these facts, we have to determine more effectively the harm reduction strategies that seem to be working, and build on these successes. There are already an estimated 276 million firearms within the United States, and these firearms have a service life of up to one hundred years. Consequently, technological changes (the so called "smart gun") realistically might take decades after they are introduced before they have a meaningful effect.

While many public health scholars advocate for introducing additional laws to regulate the use of firearms, we question whether legislation on its own will have much of an impact on unintentional firearms deaths (see Hahn et al., 2003). Consistent with the observations made by Klein (1980), the present study finds that states that are characterized by high rates of alcohol use and smoking, as well as officially reported sexually transmitted diseases, and births to teenagers also will have high rates of unintentional firearms fatalities, irrespective of the number of firearms in circulation. People who engage in these risky or self-destructive behaviors are probably poor candidates to follow firearms legislation that mandates safe storage (Kleck, 1991) or take other precautions with their guns. While on their face child access prevention laws seem to be a common sense approach to firearms safety, Jacobs (2002, p. 195) observed that: While trigger lock proposals seek to regulate manufacturers, safe storage laws seek to regulate individual gun owners, a tougher challenge. Indeed such laws are not really enforceable. The police will not be able to determine whether a firearm is safely stored. And even if somehow they did identify an unsafely stored weapon, criminal prosecution is hardly likely and punishment, if imposed at all, would be very light. Therefore, such laws really 
amount to little more than exhortations to gun owners to be safety conscious. Most gun owners are already safety conscious, but those who are currently blasé about loaded weapons in the home may not be easily persuaded to change their behavior.

Our study is a state-level examination of fatalities, and it is difficult to make generalizations about individual conduct from the macro level of analysis -- yet our findings suggest that jurisdictions with high rates of risky behavior are apt to have fatal accidents at a higher rate than places where lifestyles are more risk-averse -- regardless of the mechanism. An important next step, therefore, would be more extensive individual-level examination of the circumstances or context surrounding these injuries, better understanding the behavioral characteristics of the actual individual(s) involved, and whether safety devices such as trigger locks were present (Kleck, 2002).

The findings presented in this research suggest that interventions applied to those who are already safety-conscious may be redundant. If we want to reduce accidental firearms deaths, we should strive to develop interventions that target those who engage in risky behaviors. One positive outcome of such a strategy is that by reducing firearms fatalities, we also should reduce residential fires, motor vehicle accidents, and occupational injuries as well.

\section{References}

Americans for Gun Safety Foundation. (2002). Broken records: How America's faulty background check system allows criminals to get guns. Retrieved December 10, 2002, from http://w3.agsfoundation.com/media/BRReport.pdf

Azreal D., Cook P. J. \& Miller, M. (2004). State and local prevalence of firearms ownership: Measurement, structure and trends. Journal of Quantitative Criminology, in press.

Barber, C., Hemenway, D., Hochstadt, J. \& Azreal, D. (2002). Underestimates of unintentional firearm fataliltites: Comparing Supplementary Homicide Report data with the National Vital Statistics system. Injury Prevention, 8, 252-256.

Beaman V., Annest, J. L., Mercy, J. A., Kresnow, M. \& Pollock, D. A. (2000). Lethality of firearmrelated injuries in the United States population. Annals of Emergency Medicine, 35, 258-266.

Brady Campaign. (2003). Child access prevention laws. Retrieved March 18, 2003, from http://www.bradycampaign.org/facts/gunlaws/cap.asp

Bureau of Alcohol, Tobacco \& Firearms. (2000). Commerce in Firearms in the United States. Washington, DC: Bureau of Alcohol, Tobacco and Firearms.

Bureau of Transportation Statistics. (2003). National transportation statistics, 2002. Washington, DC: Bureau of Transportation Statistics.

Caruso, R., Jara, D. \& Swan, K. (1999). Gunshot wounds: Bullet caliber is increasing. Journal of Trauma, 46, 462-465.

Centers for Disease Control \& Prevention. (2003). Mortality (fatal injury) reports. Retrieved November 25, 2003, from http://webapp.cdc.gov/sasweb/ncipc/mortrate.html

Cummings, P., Grossman, D. C., Rivara, F. P., \& Koepsell, T. D. (1997). State gun safe storage laws and child mortality due to firearms. Journal of the American Medical Association, 278, 1084-1086.

Di Maio, V. (1985). Gunshot wounds: Practical aspects of firearms, ballistics and forensic techniques. New York: Elsevier.

Firearms Injury Center at Penn. (2002). Firearm injury in the United States. Retrieved online December 29, 2003, from http://www.uphs.upenn.edu/ficap/america.htm

Frattaroli, S., Webster, D. W., \& Teret, S. P. (2002). Unintentional gun injuries, firearm design, and prevention: What we know, what we need to know, and what can be done. Journal of Urban Health, 79, 49-59.

Geberth, V. (1996). The staged crime scene. Law and Order, 44, 89-93. 
Graduate Institute of International Studies. (2003). Small arms survey 2003: Development denied. New York: Oxford University Press.

Greene, W. E. (2000). Econometric analysis. New York: Prentice Hall.

Hahn, R. A., Bilukha, O. O., Crosby, A., Fullilove, M. T., Liberman, A., Moscicki, E. K., et al. (2003). First reports evaluating the effectiveness of strategies for preventing violence: Firearms laws. Morbidity and Mortality Weekly Report, 52, 11-20.

Hanzlick, R., Hunsaker, J., \& Davis, G. (2002). A guide for manner of death classification. St. Louis, MO: National Association of Medical Examiners

Harris, A. R., Thomas, S. H, Fisher, G. A., \& Hirsch, D. J. (2002). Murder and medicine: The lethality of criminal assault 1960-1999. Homicide Studies, 6, 128-66.

International Hunter Education Association. (2004). Listing of hunter education requirements for all of North America. Retrieved January 10, 2004, from http://www.ihea.com/infodb/

Ismach, R. B., Reza, A., Ary, R., Sampson, T. R., Bartolomeos, K., \& Kellerman, A. L. (2003). Unintended shootings in a large metropolitan area: An incident-based analysis. Annals of Emergency Medicine, 41, 32-34.

Jacobs, J. B. (2002). Can gun control work? New York: Oxford University Press.

Jaret, P. (2000). What doctors can do about guns. Hippocrates 14(7). Retrieved December 15, 2003, from http://www.hippocrates.com/archive/July2000/07features/07feat_GunSafety.html

Kates, D. B. (2001). Guns and public health: Epidemic of violence or pandemic of propaganda? In G. Kleck and D.B. Kates (Eds.), Armed: New perspectives on gun control (pp. 31-106). Amherst, NY: Prometheus Books.

Kleck, G. (1991). Point blank: Guns and violence in America. New York: Aldine de Gruyter.

Kleck, G. (2001). Measures of gun ownership levels for macro-level crime and violence research. Paper presented at the annual meeting of the American Society of Criminology, Atlanta, GA: Nov. 710, 2001.

Kleck, G. (2002). Research agenda on guns, violence and gun control. Journal on Firearms and Public Policy, 14, 51-72.

Klein, D. (1980). Societal influences on childhood accidents. Accident Analysis and Prevention, 12, 275281.

Lalloo, R., Sheiham, A., \& Nazroo, J.Y., (2003). Behavioral characteristics and accidents: Findings from the Health Survey for England 1997. Accident Analysis and Prevention, 35, 661-667.

Lott, J., \& Whitley, J. (2001). Safe-storage gun laws: Accidental deaths, suicides, and crime. Journal of Law and Economics, 44, 659-689.

Mays, G. L., \& Ruddell, R. (2003). Child access prevention legislation and firearms mortality in the United States and Canada. Paper presented at the Western Social Science Association annual meeting, Las Vegas, NV: April 9-12, 2003.

Miller M., Azrael, D., \& Hemenway, D. (2001). Firearm availability and unintentional firearm deaths. Accident Analysis and Prevention, 33, 477-484.

Miller, M., Azreal, D., \& Hemenway, D. (2002). Firearm availability and unintentional firearm deaths, suicide, and homicide among 5-14 year olds. Journal of Trauma, 52, 267-275.

Nance M. L., Branas C.C., Wiebe D. J., Elliot M. R., \& Schwab C. W. (2003). Effect of ruralization on unintentional firearm mortality in the United States. Presented at the American Public Health Association Annual Meeting, November, 2003.

Neal, M. (2000). Risk aversion: The rise of an ideology. In L. Jones (Ed.), Safe enough? Managing risk and regulation (pp. 13-30). Vancouver, CAN: Fraser Institute.

Noland, R. B. (2003). Traffic fatalities and injuries: The effect of changes in infrastructure and other trends. Accident Analysis and Prevention, 35, 599-611.

Norris, F. H., Matthews, B. A., \& Riad, J. K. (2000). Characterological, situational, and behavioral risk factors for motor vehicle accidents: A prospective examination. Accident Analysis and Prevention, 32, 505-515. 
Open Society Institute (2000). Gun control in the United States: A comparative study of state firearm laws. Retrieved December 1, 2002, from http://www.soros.org

Peltzer, K., \& Renner, W. (2003). Superstition, risk-taking and risk perception of accidents among South African taxi drivers. Accident Analysis and Prevention, 35, 619-623.

Ruddell, R., \& Mays, G. L. (2002). Research note: Using the NIJ threat level scale to classify firearms lethality. The Justice Professional, 15, 319-327.

Ruddell, R., \& Mays, G. L. (2004). Risky behavior, guns, firearms legislation and unintentional firearms fatalities. Youth Violence and Juvenile Justice, 2, 342-358.

Rushforth, N., Hirsch, C., Ford, A., \& Adelson, L. (1974). Accidental firearm fatalities in a metropolitan county (1958-1973). American Journal of Epidemiology, 100, 499-505.

Schaechter, J., Duran, I., De Marchena, J., Lemard, G., \& Villar, M. (2003). Are “accidental” gun deaths as rare as they seem? A comparison of medical examiner manner of death coding with an intentbased classification approach. Pediatrics, 111, 741-744.

Sumer, N. (2003). Personality and behavioral predictors of traffic accidents: Testing a contextual mediated model. Accident Analysis and Prevention, 35, 949-964.

Svenson, J. E., Spurlock, C., \& Nypaver, M. (1996). Pediatric firearm-related fatalities: Not just an urban problem. Archives of Pediatric Adolescent Medicine, 150, 583-587.

Teret, S., \& Webster, D. (1999). Reducing gun deaths in the United States. British Medical Journal, 318, 813-818.

Turner C., McClure, R., \& Pirozzo, S. (2004). Injury and risk-taking behavior: A systematic review. Accident Analysis and Prevention, 36, 93-101.

Turvey, B. (2000). Staged crime scenes: A preliminary study of 25 cases. Journal of Behavioral Profiling, $1,1-15$.

U.S. Department of Health and Human Services. (2000). Healthy people 2010: Understanding and improving health. Washington, DC: Heath and Human Services.

U.S. Fish and Wildlife Service. (2002). 2001 National survey on fishing, hunting and wildlife-associated recreation. Washington, DC: Fish and Wildlife Service.

Warnick, R. (2000). Recreation participation trends: Generational patterns and change. Retrieved March 15, 2003, from http://www.prr.msu.edu/trends2000/pdf/warnick generations.pdf

Wiebe, D. J. (2003). Firearms in US homes as a risk factor for unintentional gunshot fatality. Accident Analysis and Prevention, 36, 711-716.

Wintemute, G. (2000). Guns and gun violence. In A. Blumstein \& J. Wallman (Eds.), The crime drop in America (pp. 45-96). Cambridge, UK: Cambridge University Press.

\section{Acknowledgements}

An earlier version of this paper was presented at the annual meeting of the Western Social Science Association in Las Vegas, NV April 9-12, 2003.

Author Information

Rick Ruddell, Assistant Professor

Department of Political Science

California State University, Chico

Chico, CA 95929

E-Mail: rruddell@csuchico.edu

G. Larry Mays, Professor

Department of Criminal Justice

New Mexico State University

Las Cruces, NM 88003 


\section{Appendix A}

Unintentional State Fatalities: Zero-Order Correlation Matrix, Means, and Standard Deviations

\begin{tabular}{|c|c|c|c|c|c|c|c|c|c|c|c|c|}
\hline & & (1) & (2) & (3) & (4) & (5) & (6) & (7) & (8) & (9) & (10) & (11) \\
\hline 1 & All Accidental Fatalities & ----- & & & & & & & & & & \\
\hline 2 & Motor Vehicle Fatalities & $.920 *$ & ----- & & & & & & & & & \\
\hline 3 & Res. Fire Fatalities & $.545 *$ & $.576 *$ & ----- & & & & & & & & \\
\hline 4 & Drowning Fatalities & $.583 *$ & $.480 *$ & $.333^{*}$ & ----- & & & & & & & \\
\hline 5 & Occupational Fatalities & $.700 *$ & $.622 *$ & $.288 *$ & $.776 *$ & ----- & & & & & & \\
\hline 6 & Emergency Dept. Visits & .206 & $.296 *$ & $.642 *$ & -.052 & -.003 & ----- & & & & & \\
\hline 7 & All Firearms Deaths & $.807 *$ & $.836 *$ & $.704^{*}$ & $.384 *$ & $.444 *$ & $.401 *$ & ----- & & & & \\
\hline 8 & Percent Urban & $-.650 *$ & $-.616 *$ & $-.353 *$ & $-.407^{*}$ & $-.625 *$ & -.207 & $-.521 *$ & ----- & & & \\
\hline 9 & Risky Behavior & $.401 *$ & $.471^{*}$ & $.564^{*}$ & $.322 *$ & .132 & .200 & $.479 *$ & .189 & ----- & & \\
\hline 10 & Inactivity & $.527 *$ & $.553 *$ & $.743^{*}$ & $.325 *$ & .271 & $.559 *$ & $.716^{*}$ & -.273 & $.470 *$ & ----- & \\
\hline 11 & Seat Belt Usage & $-.304 *$ & $-.322 *$ & $.402^{*}$ & -.172 & $-.334 *$ & $-.506^{*}$ & $-.323^{*}$ & $.442^{*}$ & .001 & -.259 & ----- \\
\hline & Mean & 38.63 & 17.02 & 1.12 & 1.35 & 5.54 & 377.96 & .34 & 67.90 & .00 & .00 & 70.32 \\
\hline & S.D. & 8.70 & 5.47 & .53 & .58 & 3.26 & 76.64 & .25 & 20.58 & 1.00 & 1.00 & 9.39 \\
\hline
\end{tabular}




\section{Appendix B}

Unintentional State Firearms Fatalities: Zero-Order Correlation Matrix, Means, and Standard Deviations

\begin{tabular}{|c|l|c|c|c|c|c|c|c|c|}
\hline & & $\mathbf{( 1 )}$ & $\mathbf{( 2 )}$ & $\mathbf{( 3 )}$ & $\mathbf{( 4 )}$ & $\mathbf{( 5 )}$ & $\mathbf{( 6 )}$ & $\mathbf{( 7 )}$ & $\mathbf{( 8 )}$ \\
\hline 1 & $\begin{array}{l}\text { All Firearms } \\
\text { Deaths }\end{array}$ & ----- & & & & & \\
\hline 2 & Percent Urban & $-.521^{*}$ & ----- & & & & & & \\
\hline 3 & $\begin{array}{l}\text { Risky } \\
\text { Behavior }\end{array}$ & $.479^{*}$ & .189 & ----- & & & & \\
\hline 4 & Inactivity & $.716^{*}$ & -.273 & $.470^{*}$ & ----- & & & & \\
\hline 5 & $\begin{array}{l}\text { Firearms } \\
\text { Density }\end{array}$ & $.731^{*}$ & $-.509^{*}$ & $.418^{*}$ & $.608^{*}$ & ------ & & & \\
\hline 6 & $\begin{array}{l}\text { Child Access } \\
\text { Law }\end{array}$ & $-.537^{*}$ & $.499^{*}$ & -.030 & $-.320^{*}$ & $-.567^{*}$ & ----- & & \\
\hline 7 & $\begin{array}{l}\text { Overall Gun } \\
\text { Laws (ln) }\end{array}$ & $-.487^{*}$ & $.638^{*}$ & -.097 & $-.397^{*}$ & $-.699^{*}$ & $-.590^{*}$ & ----- & \\
\hline 8 & $\begin{array}{l}\text { Background } \\
\text { Checks }\end{array}$ & $-.510^{*}$ & $-.306^{*}$ & $-.306^{*}$ & $.328^{*}$ & $-.467^{*}$ & $-.472^{*}$ & $.473^{*}$ & ----- \\
\hline & & & & & & & \\
\hline
\end{tabular}




\section{Appendix C}

Risky Behavior and Inactivity Factors: Correlations and Component Matrix

\begin{tabular}{|c|c|c|c|c|c|c|c|c|}
\hline & $\begin{array}{c}\text { Risky Behavior } \\
\text { Factor }\end{array}$ & (1) & (2) & (3) & (4) & (5) & (6) & (7) \\
\hline 1 & $\begin{array}{l}\text { Chlamydia Rate } \\
(2000,2001)\end{array}$ & $\begin{array}{ll}---- \\
\end{array}$ & & & & & & \\
\hline 2 & $\begin{array}{l}\text { Gonorrhea Rate } \\
(2000,2001)\end{array}$ & $.741^{*}$ & $\begin{array}{l}---- \\
\end{array}$ & & & & & \\
\hline 3 & $\begin{array}{l}\text { Per Capita } \\
\text { Ethanol (1999) }\end{array}$ & .182 & .208 & ----- & & & & \\
\hline 4 & $\begin{array}{l}\text { Smoking Rate } \\
(2000,2001)\end{array}$ & .275 & $.428 *$ & .271 & ----- & & & \\
\hline \multirow[t]{3}{*}{5} & $\begin{array}{l}\text { Teen Birth Rate } \\
(2000,2001)\end{array}$ & $.658^{*}$ & $.631^{*}$ & $.515 *$ & $.331^{*}$ & ----- & & \\
\hline & & & & & & & & \\
\hline & Inactivity Factor & & & & & & & \\
\hline 1 & $\begin{array}{l}\text { Overweight Rate } \\
(2000,2001)\end{array}$ & & & & & & ----- & \\
\hline \multirow[t]{2}{*}{2} & $\begin{array}{l}\text { Inactive Days } \\
(2000,2001)\end{array}$ & & & & & & $.352 *$ & ----- \\
\hline & $\begin{array}{l}\text { Component } \\
\text { Matrix }\end{array}$ & .678 & .730 & .276 & .333 & .757 & .822 & .822 \\
\hline
\end{tabular}

$* \mathrm{p}<.05 ; \ln =\log$ transformed 